\title{
EPILEPSY IN MONGOLISM
}

\author{
BY \\ BRIAN H. KIRMAN \\ From the Fountain Hospital, Tooting, London
}

(Received for Publication February 9, 1951)

It is generally agreed that epilepsy is rare in mongolism. Penrose (1949) states that it is no more common in mongolism than in the general population. The older authors (Ireland, 1877 and 1898; Barr, 1904; Kelynack, 1915) do not mention epilepsy in mongolism, nor does Benda (1947) in his extensive review of the subject. This is surprising in view of the frequency of epilepsy among other groups of imbeciles. It is, however, in keeping with the absence of evidence of focal lesions in the brains of most mongolian imbeciles. Engler (1949), it is true, mentions that $8 \cdot 85 \%$ of his cases were epileptics, but it would appear that his experience is unusual; compare his statement that after many years' experience he has seen only one mongol with red hair. Of 91 patients with mongolian imbecility at the Fountain Hospital only one had fits.

\section{Case Report}

The baby, a boy, was born on November 1,1939. The family history showed that there was no history of fits or mental deficiency in any member of the family. The father was 41 and the mother was 43 at the time of the child's birth. The father is a tailor. The mother suffered from a broken leg during pregnancy. In 1945 she was suffering from leukaemia.

The siblings in the family are shown in Table 1.

TABLE 1

SiblingS In $\cdot$ FAMILY

\begin{tabular}{|c|c|c|c|}
\hline & Sex & Age (1945) & Comments \\
\hline $\begin{array}{l}1 . \\
2 . \\
3 . \\
4 . \\
5 .\end{array}$ & $\begin{array}{l}\mathbf{M} \\
\mathbf{M} \\
\mathbf{F} \\
\mathbf{F} \\
\mathbf{M}\end{array}$ & $\begin{array}{r}22 \\
17 \\
14 \\
5\end{array}$ & $\begin{array}{c}\text { Stillborn about } 1922 \\
\text { Healthy, married } \\
\text { ", at home } \\
\text { Patient }\end{array}$ \\
\hline
\end{tabular}

The patient's previous history showed that the confinement was very difficult, and the child is said nearly to have died. Mental deficiency was noted at an early age: mongolism and congenital abnormality of the heart were diagnosed. In April, 1942, the child was said to have had a cerebral haemorrhage, followed by left hemiplegia. He became suddenly ill, was comatose for two days, and six days later it was noted that one eye was closed and the left arm and leg were held still.

When he was admitted to hospital on August 15, 1945, he did not know his name. He could say only a few single words. He did not grasp objects put into his hand, and did not obey simple commands. He did not play with toys. He was incontinent of urine and faeces. He could not stand, walk, or use a spoon. He showed little interest in his surroundings.

He had the typical features of mongolism. The head measurements were: length $6 \frac{1}{4}$ in., breadth $5 \frac{1}{2}$ in. (cranial index 0.88 ), circumference $19 \frac{1}{4}$ in. $\mathrm{He}$ was somewhat pigeon-chested. There were a few râles in the left chest and a harsh murmur in the pulmonary area. He had a left spastic hemiplegia. The right side showed the hypotonus usual in mongolism, and he could put the foot behind his head with ease. There was well marked finger clubbing. The Wassermann and Meinicke reactions were negative.

It was noted soon after admission that he was delicate. He developed enteritis, stomatitis, and later bronchitis, becoming very cyanosed. Bronchitis persisted with occasional low pyrexia. On one occasion in 1946, he became deeply cyanosed and collapsed. The cyanosis persisted with varying intensity until his death. The finger clubbing increased and the toes were also markedly affected. In 1947 the abdomen was found to be grossly distended, though free fluid was not detected. At that time he had learnt to feed himself and to obey simple commands. He was friendly and usually was clean in - his habits.

Epileptic fits began in 1948, seven months before his death. They were major generalized attacks, each of which perceptibly increased the circulatory embarrassment. A total of 29 occurred.

In June, 1948, gross oedema of the legs appeared. It was thought that ascites and enlargement of the liver were present. In September of the same year he became more cyanosed and distressed, finally collapsing and dying.

At necropsy it was found that the body was that of a well nourished boy with marked 'mongol' features. There was pronounced cyanosis especially of the face and mucous membranes. Finger clubbing was extreme. All the abdominal organs showed congestive changes. 


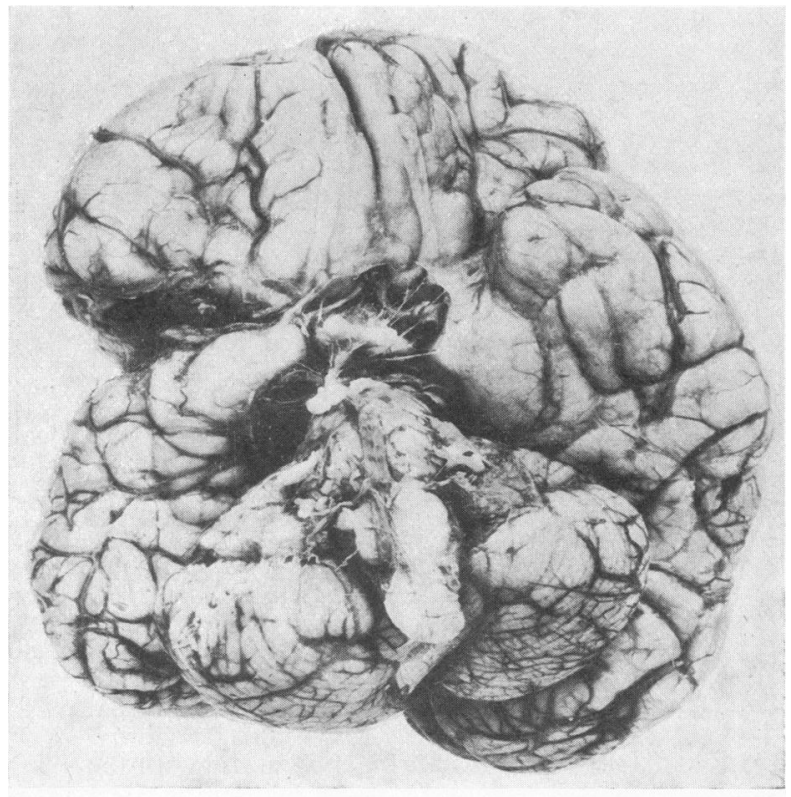

FIG. 2.

FIG. 2.-View of the brain from below. The right internal and middle cerebral arteries are markedly narrower, probably as a result of occlusion of the internal carotid artery by an embolus or thrombus in the past. The floors and walls of the widened lateral fissure represent the lower boundary of the cerebral defect, and are covered by thickened meninges. On the side opposite to this lesion the left cerebellar hemisphere is smaller than its fellow.

Fig. 3.-Cerebrum sectioned horizontally. All the tissue lateral and medial to the right lateral ventricle is reduced to a membrane only $1 \mathrm{~mm}$. thick in places. The caudate nucleus survives, but is much smaller than on the opposite side. The lentiform nucleus, thalamus, and internal capsule are absent or rudimentary.

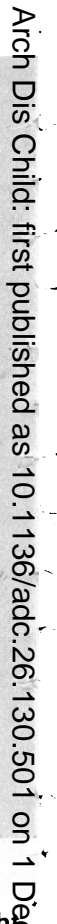

FIG. 1.-View of brain from above showing the righధ cerebral hemisphere, shorter and narrower than the lef̣ with a large irregular dark sunken defect.

무유

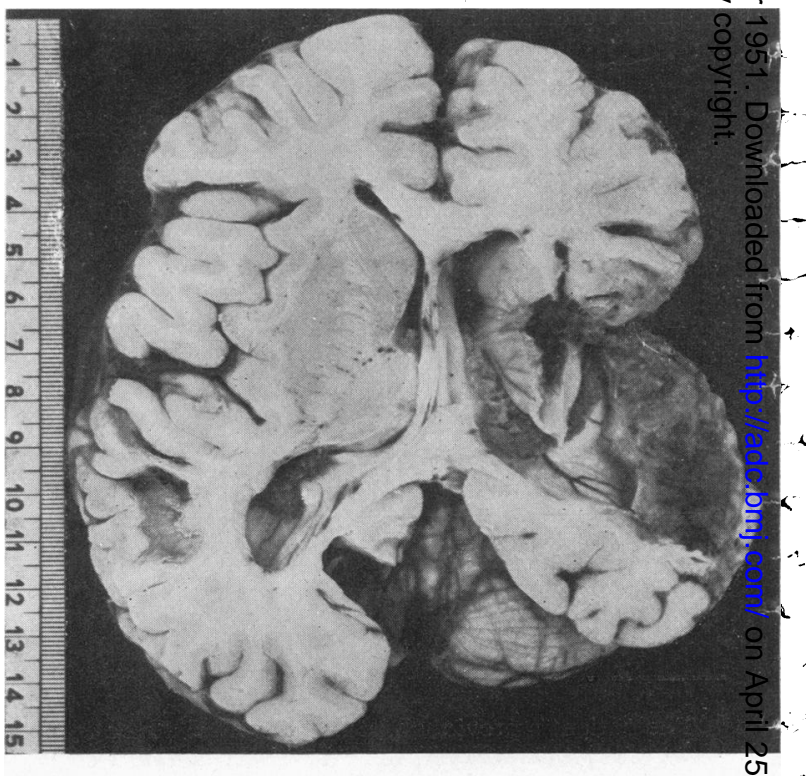

FIG. 3. 
The left kidney was extremely small and the right correspondingly hypertrophied. The lungs were also markedly congested. The heart was enlarged and showed Fallot's tetralogy. The right ventricle occupied more of the anterior surface than is usual. Both atria were distended. There was virtually only one auricular cavity, the septum being represented by only a few fibrous strands. The interventricular septum was also grossly defective, with an opening $35 \mathrm{~mm}$. wide. The tricuspid and mitral valves were not differentiated. There was pulmonary stenosis, the pulmonary artery being only $5 \mathrm{~mm}$. wide at its origin. The pulmonary valves were absent.

The meninges participated in the general congestion. There was atrophy of the right cerebral hemisphere, especially in the anterior part of the parietal lobe adjacent to the Sylvian fissure.

\section{Commentary}

In view of the history and pathology in this case there is little doubt that the unusually severe degree of heart defect led to a cerebral vascular catastrophe and that the epilepsy was a sequel to this and was not due to the cerebral abnormalities of mongolism. The surprising thing about the case is that with such a grossly inefficient heart it was possible for the nursing staff to keep him alive for so long. It will be noted that the fits did not start immediately after the development of the hemiplegia but began only a few months before death. It seems probable that the rapidly failing circulation with consequent cerebral congestion and anoxia contributed to the development of epilepsy.

It was customary not long ago (Tredgold, 1929; Brain, 1947) to divide both mental defect and epilepsy into 'primary' and 'secondary'. (The terms 'idiopathic' and 'symptomatic' are used of epilepsy.) These terms are without value and in fact misleading. Bateman (1936) studied the brains of 178 epileptics and found only two normal. It is true that other workers have found a lower proportion of gross anomalies. It is clear that a study of a similar series of brains from cases of gross mental defect would have similar results, though unfortunately no such examination has yet been carried out on an adequate scale (despite the work of Ashby and Stewart, 1933, 1934, 1935, in limited areas of this field). Since the imbeciles and idiots on the one hand and epileptics on the other, have in common a localized abnormality of the brain in a majority of cases, it is not surprising that many imbeciles and idiots should be epileptics and vice versa. The peculiar feature of the group of mongolian imbeciles, who form some $10 \%$ of the population of this hospital, and more in the younger age groups, is the extreme diffuseness of the cerebral lesion and the general retardation of the growth of the brain. A special feature is the relative smallness of the cerebellum and the brain stem. This may be related to the low muscular tone and acrobatic potentialities of the 'mongol' and may also be significant in relation to his immunity from epilepsy.

Apart from its relationship to more general problems the absence of epilepsy in mongolism is of practical importance since it is connected with the relative tractability of this group and does something to offset their generally low level of occupational attainment.

My thanks are due to Dr. M. K. Beattie for the necropsy report, to Dr. M. C. H. Dodgson for the report on the brain, and to Mr. J. E. Stevens for the photographs.

\section{REFERENCES}

Ashby, W. R., and Stewart, R. M. (1933). J. Neurol. Psychopath., 13, 303.

- Psychopath., 13, $\begin{aligned} & \text { (1934). Ibid., 14, } 217 . \\ & - \text { (1935). Ibid., 16, } 26 .\end{aligned}$

Barr, M. W. (1904). 'Mental Defectives.' Philadelphia.

Bateman, J. F. (1936). Arch. Neurol. Psychiat., Chicago, $36,578$.

Benda, C. E. (1947). 'Mongolism and Cretinism.' London.

Brain, W. R. (1947). ' Diseases of the Nervous System, 3rd ed., p. 886 . London.

Engler, M. (1949). 'Mongolism,' pp. 48, 73. Bristol. Ireland, W. W. (1877). 'Idiocy and Imbecility.' London. (1898). ' Mental Affections of Children.' London. Kelynack, T. N. (1915). 'Defective Children.' London. Penrose, L. S. (1949). ' The Biology of Mental Defect,' p. 182. London.

Tredgold, A. F. (1929). ' Mental Deficiency,' 5th ed., p. 26. London. 